\title{
Strategizing in Digital Application Marketplaces
}

\author{
Ahmad Ghazawneh ${ }^{1,2}$ \\ ${ }^{1}$ School of Information Technology \\ Halmstad University \\ Halmstad, Sweden \\ Email: ahmad.ghazawneh@hh.se
}

${ }_{2}^{2}$ Department of Business IT

IT University of Copenhagen

Copenhagen, Denmark

Email: agha@itu.dk

\section{Osama Mansour}

Jönköping International Business School

Jönköping University

Jönköping, Sweden

Email: osama.mansour@ju.se

\section{Magnus Bergquist}

School of Information Technology

Halmstad University

Halmstad, Sweden

Email: magnus.bergquist@hh.se

\begin{abstract}
Digital application marketplaces have become an important strategizing device for many product developing firms. However, creating and sustaining digital application marketplaces are challenging tasks and only little empirical evidence exists about the role and nature of strategy for these marketplaces and how such strategizing actually unfolds in practice. Drawing on a case study of Apple's App Store, we applied a strategy-as-process perspective to investigate the role of a digital application marketplace in the development of a digital platform. Our analysis identifies and describes three different strategies in the App Store case: monetizing, governing and enhancing, and demonstrates how they were enacted proactively or reactively to support the development of the platform.
\end{abstract}

Keywords digital platforms, digital application marketplaces, Strategy-as-Process, strategizing, AppStore 


\section{Introduction}

Digital application marketplaces are rapidly transforming how product developing firms gather benefits from distributing, brokering, and operating applications by third-party developers (Meyer and Seliger, 1998; West and Mace 2010). Research has recently recognized the importance of such marketplaces for value creation in larger digital ecosystems (Ghazawneh and Mansour, 2015). These marketplaces act as foundational platforms that facilitate innovation in web systems and e-business portals (Evans et al. 2006) smart mobile phones (Tiwana et al. 2010; Yoo et al. 2010) and automotive technologies (Henfridsson and Lindgren 2010). In this way, they play a central role in building and sustaining the business of the platform (Evans et al. 2006; Messerschmitt and Szyperski 2003).

The success of digital application marketplaces is significant. Apple's AppStore, for instance, has generated more than 2.4 million apps, 180 billion downloads, and $\$ 38.5$ billion in revenues in less than ten years. Yet, developing and operating a digital application marketplace is not a guarantee for making it successful. In fact, firms such as Nokia, BlackBerry and Google have operated their own marketplaces without necessarily achieving the same level of success. This has stimulated significant interest in the strategic role of digital application marketplaces for digital platform business.

Different aspects of digital application marketplaces have been highlighted including marketplace typology which helps in tracing the underlying assumptions that underpin the object of interest for how different stakeholders generate value for the platform (Rudmark and Ghazawneh, 2011; Ghazawneh and Henfridsson, 2015). Also, the role of digital application marketplaces in value creation has been accounted for (Ghazawneh and Mansour, 2015). However, less is known about how a platform owner develops strategies for the digital application marketplace.

Strategizing practices are the activities through which an organization's resources are aligned (Whittington, 1996). Strategizing is a complex and partly messy process due to the fact that requirements and opportunities change and are difficult to anticipate (Galliers, 2007). A strategizing organization therefore develops practices and moves to deal with unforeseen incidents and build capacity to explore opportunities that are gradually aligned with the organization's goals (Besson \& Rowe, 2012; Chia and MacKay 2007; Henfridsson and Lind, 2014). To understand how an organization strategizes a digital application marketplace, we are seeking to answer the following question: What characterizes the strategizing practices of a platform owner in attempts to create and sustain a digital application marketplace?

In order to address this research question, a single case study (Yin 2009) of Apple's digital application marketplace, AppStore, was designed, and a detailed empirical analysis of Apple's strategizing their AppStore was engaged. The remainder of this paper is structured as follows: the next section offers a review of related literature. It is followed by a presentation of the strategy-as-process perspective which is the theoretical basis in the paper. Then, an outline of the research methodology is provided. Later, the results from data analysis are presented. Finally, key conclusions and implications are developed.

\section{Related Literature and Conceptual Background}

\subsection{Digital Platforms and Marketplaces}

The concept of digital platforms is based on the development of complementary assets. It enables individuals/firms to harness software development technologies (Baldwin and Woodard, 2009; Franke and von Hippel, 2003; Ghazawneh, 2011; West, 2003) as a foundation to build complementary digital services (Gawer, 2008). Digital platforms can be found in various settings such as personal computers (Bresnahan and Greenstein, 1999), video game consoles (Iansiti and Zhu, 2007; Romberg, 2007), smartphones (Tiwana et al., 2010; Yoo et al., 2010), web systems (Evans et al., 2006), automotive technologies (Henfridsson and Lindgren, 2010) and music industry (Tilson et al., 2013)

The complementary digital services are designed, developed and employed by third-party developers (Boudreau, 2012; Evans et al., 2006; Messerschmitt and Szyperski, 2003; Ghazawneh and Henfridsson, 2015), and are in the form of applications, or "apps". These apps extend the functionality of digital platforms (Baldwin and Clark, 2000), address the needs of heterogeneous end-users, and shift the focus of the platform owner from producing software into distributing, brokering, and operating apps (Meyer and Seliger, 1998; West and Mace, 2010). The importance of developed apps and services is recognized in building digital platforms (Bergvall-Kåreborn et al., 2010; Bosch, 2009; Boudreau, 2012; Hanseth and Lyytinen, 2010). Therefore, platform owners attempt to sustain platform innovation by: (1) continuously attracting third-party developers (Bergvall-Kåreborn et al., 2010), (2) providing manifold of social and technical resources (Ghazawneh and Henfridsson, 2013), (3) establishing digital 
distribution channels (Ghazawneh and Henfridsson, 2015), and (4) building healthy digital ecosystems that accommodate the stakeholders' needs (Bosch, 2009; Messerschmitt and Szyperski, 2003).

Digital application marketplaces, commonly known as App Stores, are essential parts of digital platforms. A digital application marketplace is defined as "a platform component that offers a venue for exchanging applications between developers and end-users belonging to a single or multiple ecosystem" (Ghazawneh and Henfridsson, 2015, p. 4). It primarily facilitates the distribution of apps and services as well as enables marketplace functionalities such as payments, commissions, and the execution of transactions (Amberg et al., 2010; Han and Ghose, 2012). It also allows users to search, browse, download, rate and review applications, and offers third-party developers the ability to publish, integrate, update and promote their apps (Magnusson and Nilsson, 2013).

\subsection{Strategy-as-Process Perspective}

It has long been acknowledged that both deliberate and emergent patterns of action drive and enable strategy content (Mintzberg, 1978). Within Information Systems, much literature has focused on deliberate strategizing (Henfridsson \& Lind, 2014). The pervasiveness of digital application marketplaces along the evolution of digital ecosystems, however, makes deliberate strategizing more complex. This complexity is manifested in emergent interactions among multiple actors as they collaboratively engage in value co-creation in today's digital application marketplaces (Ghazawneh and Mansour, 2015). Strategy making in such an environment becomes a continuous process where flexibility, agility, and improvisation are increasingly necessary for devising strategic actions and practices (El Sawy, 2010) as focus shifts from strategy content (Henfridsson and Lind, 2014) into emergent strategy and strategy process (Pettigrew, 1992). This is not to say that the strong belief in deliberate strategizing is weakening, but rather to recognize strategizing complexity that may arise from messy, non-linear, and discontinuous interactions in a digital ecosystem (Besson and Rowe, 2012). Strategizing can then be seen as "grounded in the ongoing practices of organizational actors and emerges out of their (tacit and not so tacit) accommodations to and experiments with the everyday contingencies, breakdowns, exceptions, opportunities, and unintended consequences that they encounter" (Orlikowski, 1996, p. 65).

In seeking to understand strategizing in digital application marketplaces, strategy must thus be studied as process - strategy-as-process. This has been formulated in strategy research as the strategy-aspractice perspective which emphasizes strategizing as an ongoing activity (Jarzabkowski et al., 2007, Galliers, 2011) and recognizes practices (i.e. what actors actually do) as part of a strategizing process. The strategy process research is oriented towards the emergence of firms' strategies, which is different from strategy content research where the orientation is on strategic decisions and how they relate to the industrial context of firms (Henfridsson \& Lind, 2014; Besson \& Rowe, 2012; Chia and MacKay 2007). First, the adoption of a strategy-as-process perspective (Chia and MacKay 2007; Johnson et al. 2003; Jarzabkowski 2008; Whittington 2014) provides a basis for understanding the strategizing around digital application marketplaces. Second, the implementation of a strategy is viewed as a process of organizational becoming (El Sawy, 2010; Benson 1977; Orlikowski 2000), which is similar to our view of the implementation of a digital application marketplace strategy as a process of ecosystem becoming. Third, this view deals with the daily processes and practices of creating, sensing, and responding to emerging issues, rather than the content of the applied generic strategies such as cost-leadership, product differentiation, or segmentation (Porter 1980).

A strategizing process has three different interacting elements: strategic actors, strategic moves and strategic practices (Johnson et al. 2003; Whittington 2006). A process approach aims to unpack the interplay among these elements in the following way: First, strategy actors refer to actors in the ecosystem who strategize. They may be located at a firm level where the digital application marketplace owner may exercise control over the ecosystem, e.g., via administering strategies related to access to resources (Jarzabkowski 2008). However, other actors may respond to particular strategies and enact new strategic practices. Second, strategic moves are what strategy actors do i.e., "all the various activities involved in the deliberate formulation and implementation of strategy" (Whittington 2006, p.619), which become material for sensemaking of strategy actors (Weick 1979) and lead to new experiences, which, in turn, shapes the emergent praxis. Third, strategy practices refer to rules and resources that strategy actors draw on in their praxis (Whittington 2006). These practices can be implemented by firms (e.g., marketplaces owners) to gain advantage, either as a proactive act, or as a reactive act, i.e., as a response to other actors' strategic moves in an ecosystem (cf. Ackoff 1974). 


\section{Methodology}

\subsection{Research Design}

A single case study (Gerring 2007; Yin 2009) of Apple's AppStore was conducted in this research. Case study research is a preferred strategy to understand contemporary and complex social phenomena (Yin, 2009), especially when the research and theory are "at their early, formative stages", and research problems are practice-based where "the experiences of the actors are important and the context of action is critical" (Benbasat et al., 1987, p.369). There are a number of reasons why the study of Apple's AppStore was initiated. First of all, Apple's AppStore represents an extreme case (Yin, 2009), which is "a case that is considered to be prototypical or paradigmatic of some phenomenon of interest" (Gerring 2007, P. 101). Extreme cases are useful for theory generation as extremes typically define theoretical concepts (Gerring, 2007). This study engages in theory-generation, thus prototypical examples of the theoretical concepts are more important than having representative cases which are useful for theorytesting purposes. Second, Apple's AppStore is the largest application marketplace worldwide in terms of applications, downloads, developers and revenues. Third, there exist substantial amounts of data on Apple's AppStore, making detailed study of strategizing possible on the basis of publicly available data.

\subsection{Data Collection}

Data from secondary sources were collected covering the period between January 2007 and February 2018 (see Table 1). Yet, the use of secondary data in case study research is unusual in information systems, and a typical concern would be a perceived distance between the researcher and the context in which the data originates (cf. Walsham, 1995). The promise in the use of secondary web-based data sources, however, is the valuable production of information for case study research (Yin, 2009). Secondary data contain a large volume of data that would be impossible to obtain using typical data collection techniques such as the qualitative interview (Romano et al., 2003) and observations (Creswell, 2003). It also provides a perspective that covers key stakeholders, whose input is often necessary for sensitizing why particular initiatives were taken as a response to environmental changes (cf. Hargadon and Douglas, 2001). In addition, it is powerful for building the extensive and longitudinal database needed for contextualization of the historical background and plot of the research setting (Klein and Myers, 1999).

\begin{tabular}{|c|c|}
\hline Data Sources & Descriptions \\
\hline $\begin{array}{l}\text { Agreements } \\
\text { and guidelines }\end{array}$ & $\begin{array}{ll}\text { All publicly available case documents such as: } \\
\text { - } & \text { Registered iPhone developer agreement. } \\
\text { - } & \text { iOS human interface guidelines. } \\
\text { - } & \text { App Store Review Guidelines. } \\
\text { - } & \text { Guidelines for Using Apple Trademarks and Copyrights. }\end{array}$ \\
\hline $\begin{array}{l}\text { Conferences, } \\
\text { events, and } \\
\text { workshops }\end{array}$ & $\begin{array}{l}\text { Data collected from recorded and online-streamed Apple's conferences and events: } \\
\text { - } \quad \text { The Apple Worldwide Developers Conference (WWDC): WWDC 2007, WWDC 2008, } \\
\text { WWDC 2009, WWDC 2010, WWDC 2011. WWDC 2012, WWDC 2013, WWDC 2014, } \\
\text { WWDC 2015, WWDC 2016 and WWDC 2017. } \\
\text { - } \quad \text { Apple's SDK events: iPhone SDK 2008, iPhone SDK 2009 and iPhone SDK 2010. } \\
\text { - Apple's special events: Rock and Roll event 2009, Tablet event } 2010 \text { and Special event } \\
\text { 2011. } \\
\text { - MacWorld Conference \& Expo: MacWorld } 2007 \text { and MacWorld } 2008 .\end{array}$ \\
\hline $\begin{array}{l}\text { E-mail } \\
\text { conversations }\end{array}$ & $\begin{array}{l}18 \text { messages between Apple and developers, Apple and Federal Trade Commission } \\
\text { (FTC) and media. }\end{array}$ \\
\hline Interviews & $\begin{array}{l}\text { - Interview Philip Schiller, Apple's senior vice president of worldwide product marketing } \\
\text { with New York Times. }\end{array}$ \\
\hline Online articles & $\begin{array}{l}\text { 1850 articles from multiple online sources: } \\
\text { - } \quad \text { General magazines, newspapers and journals such as BusinessWeek.com, } \\
\text { NYTimes.com and WSJ.com. } \\
\text { - Technology-focused magazines and journals such as ComputerWorld.com, } \\
\text { MacWorld.com, and TheRegister.co.uk. } \\
\text { - Highly profiled Group-edited blogs about technology such as TechCrunch.com, } \\
\text { GigaOM.com and Engadget.com. }\end{array}$ \\
\hline Press releases & $\begin{array}{l}\text { - } \quad \text { All press releases collected from Apple's online press release library (January } 2007 \text { - } \\
\text { February 2018). } 17 \text { press releases were selected for further analysis. } \\
\text { - Developer news and announcements published by Apple at the iPhone Dev Center. }\end{array}$ \\
\hline
\end{tabular}




\subsection{Data Analysis}

Qualitative data collection often produces massive volumes of data. This is one key reason for the reputation that analyzing qualitative data is an overwhelming and cumbersome task (Patton, 2015), which happens to be especially true to the kind of data collected via secondary web-based sources in our paper. For this reason, a specialized methodology for analyzing web-based qualitative data proposed by Romano et al. (2003) was used in order to analyze our data. This generic methodology provides a structured approach to analyze dynamic, rich and large volumes of qualitative data and data that is collected via web-based sources. It consists of three key steps: elicitation, reduction and visualization.

First, relevant data segments in various formats (e.g., comments, quotes, etc.) were elicited from multiple and various data sources and then included into a database for recording study data. The elicitation process was based on the time period of January 2007 to February 2018. Data elicitation was done by careful and intensive review of all collected data types during which initial open coding (Charmaz, 2006) helped in identifying general patterns implying related themes captured as topical descriptive codes (Patton, 2015) such as AppStores, digital application marketplaces, digital distribution channels, etc. Initially, data elicitation was not deductively guided by predefined theoretical concepts from the strategy-as-process perspective. The ultimate aim was focused on organizing as much relevant data as possible to avoid chaos and confusion (Patton, 2015) that comes with a large data set like ours. Second, data reduction was done deductively using the strategy-as-process perspective as a sensitizing device for abstracting, simplifying, and transforming raw data (cf. Romano et al, 2003; Patton, 2015). To understand the process of strategizing, this step involved time-stamping selected relevant data segments that help in tracing the historical process and secure a correct timeline of events. The third and final step involved preparing time-stamped data into compressed assemblies (Romano et al., 2003) to finally draw conclusions and visualize outcomes from the data analysis process. Eventually three distinct strategies in digital application marketplaces were drawn and visualized.

\section{Findings}

\subsection{Case Setting}

Since the release of Apple's AppStore in July 10, 2008, it was growing rapidly in terms of applications, download, number of third-party developers and revenues. The AppStore has become the largest applications store worldwide. Given this success, it can be considered useful to more closely examine the strategies applied by Apple to create and sustain its store. (see Table 2). In what follows, the strategizing around the AppStore is described.

\begin{tabular}{|c|c|c|c|c|c|c|c|c|c|c|c|}
\hline Growth & 2007 & 2008 & 2009 & 2010 & 2011 & 2012 & 2013 & 2014 & 2015 & 2016 & 2017 \\
\hline Apps & $\mathrm{O}$ & $15 \mathrm{k}$ & $120 \mathrm{k}$ & $300 k$ & $500 k$ & $770 \mathrm{ok}$ & $1 \mathrm{~m}$ & $1.3 \mathrm{~m}$ & $1.5 \mathrm{~m}$ & $2 \mathrm{~m}$ & $2.4 \mathrm{~m}$ \\
\hline Dev & O & $30 \mathrm{k}$ & $80 k$ & $145 \mathrm{k}$ & $190 \mathrm{k}$ & $233 \mathrm{k}$ & $248 \mathrm{k}$ & $272 \mathrm{k}$ & $310 \mathrm{k}$ & $35 \mathrm{ok}$ & $400 \mathrm{k}$ \\
\hline Dow & $\mathrm{O}$ & $0.5 \mathrm{~b}$ & $3 b$ & $7 \mathrm{~b}$ & $18 \mathrm{~b}$ & $30 b$ & $60 b$ & $80 b$ & $110 \mathrm{~b}$ & $15 \mathrm{ob}$ & $180 b$ \\
\hline Rev & 0 & $\$ 206 \mathrm{~m}$ & $\$ 769 \mathrm{~m}$ & $\$ 1.7 \mathrm{~b}$ & $\$ 3 b$ & $\$ 8 \mathrm{~b}$ & $\$ 10 b$ & $\$ 15 b$ & $\$ 2 \mathrm{Ob}$ & $\$ 29 b$ & $\$ 38.5 \mathrm{~b}$ \\
\hline
\end{tabular}

Apps: Applications, Dev: Developers, Dow: Downloads, Rev: Revenue, k: thousand, m: million, b: billion

\subsection{Introducing the AppStore}

After the release of the first iPhone [June 27, 2007], Apple decided to use Safari web browser as the main "hub" between users and third-party developers. This strategy enabled web applications and content on the iPhone. In his keynote at Apple Worldwide Developers Conference (WWDC 2007), Apple's CEO, Steve Jobs, emphasized the main advantages of using Safari were the distribution and update process of applications:

After you [third-party developers] write them [web "apps"] you have instant distribution, you don't have to worry about distribution just put them on your Internet server. And they are really easy to update, just change the code on your own server, rather than having to go through this really complex update process.

A growing list of companies ported their applications to the Safari web browser. Google, Twitter, Facebook, Flickr, New York Times, were among the first movers to bring their applications. Scott Forstall, the Senior Vice President of iPhone software at Apple, revealed that the number of ported iPhone web applications exceeded 1,000 in a short time. However, Apple's strategy of not allowing native applications on the iPhone was criticized by huge number of developers. As a response, on October 17, 2007, Steve Jobs confirmed Apple's new strategy of allowing native applications and an exclusive digital application marketplace for users to search, browse, buy and download iPhone applications. The digital 
application marketplace was revealed at Apple's iPhone SDK event on March 06, 2008, officially released on July 10, 2008 and was called the AppStore. Steve Jobs explained the idea of the AppStore:

This is an application we've written to deliver apps to the iPhone. And we are gonna put it on every single iPhone with the next release of the software. And so our developers are gonna be able to reach every iPhone user through the AppStore.........The AppStore is going to be the exclusive way to distribute iPhone applications

\subsection{Monetizing the AppStore}

During the iPhone SDK event [March 06, 2008], the terms of the deal between Apple and applications developers was revealed. Apple shares 30\% of application sales revenues and $70 \%$ go to third-party developers. Free applications will be determined by third-party developers and will be downloaded by end-users for free. Steve Jobs introduced the deal:

We think we've got a great business deal for our developers. First of all, the developer picks the price, pick whatever price you wanna sell your app at, when we sell the app through the AppStore the developer gets $70 \%$ of the revenues right off the top, we keep 30\% to pay for running the AppStore. There are no credit card fees for the developer... there are no hosting fees... there is no marketing fees.... Its paid monthly [revenues] ...This is the best deal going to distribute application to mobile platforms...... There is no charge for free apps at all, there is no charge to the users and there is no charge to the developer.

Apple introduced a Developer Program that is designed to make resources available for third-party developers and enable the distribution of applications. The Developer Program annual fee was set at $\$ 99$ for individual developers and $\$ 299$ for enterprises. The number of developed applications exceeded 15,000 , download rate 0.5 billion and $\$ 206$ million in revenue by the end of 2008. At Apple's iPhone 3.0 Press Conference [March 17, 2009], Apple's head of iOS Product Marketing, Greg Joswiak, revealed that over 50,000 individuals and development firms joined the paid Developer Program. Few days later, on March 25, 2009, Apple updated their refund policy. Apparently, if end-users decide that they want a refund for their applications within ninety days of the date of download, Apple requires the developers to refund the full sale amount and Apple keeps its commission. The clause in the contract reads:

Apple may refund to the end-user the full amount of the price paid by the end-user for that Licensed Application. In the event that Apple refunds any such price to an end-user, You shall reimburse, or grant Apple a credit for, an amount equal to the price for that Licensed Application. Apple will have the right to retain its commission on the sale of that Licensed Application, notwithstanding the refund of the price to the end.

The AppStore was growing rapidly and daily-added applications were extremely increasing. Gaming applications dominated the AppStore. Apple leveraged this opportunity and created a new viral revenue source by introducing a new service called Game Centre. The new service which was introduced at the iPhone 4.0 event [April 08, 2010] is a social gaming network that connects multiplayers and facilitates the process of sending invitations to other users to download and play games. Apple shares $30 \%$ of games sales revenues through Game Centre. Third-party developers usually maintain their free applications by making revenues through embedded advertisements. It was reported by [Gartner] that the worldwide mobile advertising revenue generated $\$ 1.6$ billion in 2010. Google and its subsidiary AdMob accumulated more than $50 \%$ of their ad revenues through iPhone, iPod touch and iPad devices. At the iPhone 4.0 event [April 08, 2010], Apple announced its own mobile advertising service. The service was called "iAd", officially released on July 1, 2010 and competed directly with Google's AdMob. Steve Jobs commented on the new service:

Developers have to find way to make some money, and we would like to help them. Now what some of the developers are starting to do, is to put advertising into their apps... We think most of this mobile advertising really sucks, and we thought we might be able to make some contributions... It's all about helping our developers make some money through advertising so they can keep their free apps free.

Apple retains $40 \%$ of the ad revenue and the rest $60 \%$ goes to third-party developers. The initial starting price of an iAd campaign was set at $\$ 1$ million [April o8, 2010]. In order to attract small advertisers, the price was lowered to $\$ 0.5$ million [February, 2011] and lowered up to $\$ 300,000$ [July, 2011]. To deal effectively with advertisers who have gone to other ad services and to encourage third-party developers to use the service, Apple slashed iAd pricing up to $\$ 100,000$ [February, 2012] and decided to retain $30 \%$ of the ad revenue rather than their previous $40 \%$ cut.

At Apple Tablet event [January 27, 2010] a new sales and delivery service of electronic books was announced. The service, called iBooks, enables users to purchase ebooks from an associated book store. Two years later [January 19, 2012], Apple released a tool for small publishers to create their own ebooks "iBooks Author". Apple demands 30\% commission on all iBooks Author sales. Apple's end user license agreement for the iBooks Author specifically reads: 
If you charge a fee for any book or other work you generate using this software (a "Work"), you may only sell or distribute such Work through Apple (e.g., through the iBookstore) and such distribution will be subject to a separate agreement with Apple.

Many major newspapers and magazines that are charging readers for full access to their applications in the App Store criticized this move. Apple responded by loosening its new media subscription rules.

\subsection{Governing the App Store}

As to ensure the integrity of the AppStore, Apple set up an application review process. Each application submitted to the AppStore is subject to approval by Apple. Third-party developers submit their application to the AppStore and wait for approval or rejection by the AppStore review team. Third-party developers of rejected applications receive comments and feedback from the AppStore review team on the reason behind the rejection of their applications. AppStore review team gives third-party developers the chance to resubmit their rejected applications after being modified according to the review. Since the inception of the AppStore [July 10, 2008], Apple introduced a non-disclosure agreement (NDA) with third-party developers. The rejection notices and messages from the AppStore review team are covered by this agreement. The agreement prohibits third-party developers to publish or reveal their rejection notices. Apple later [October 1, 2008] dropped the (NDA), because, according to Apple statement:

It created too much of a burden on developers, authors and others interested in helping further the iPhone's success.

All applications and their updates have to go through a lengthy review process before they are deployed into the AppStore. The review process was criticized by tons of third-party developers, technology analysts and firms. First, there was no specific time delay for applications to be approved. The approval process sometimes took few days, few weeks or even months. Second, no detailed feedback was given to developers, sometimes not rather than "approved" or "rejected". Third, Apple did not publish any review guidelines that could be followed by third-party developers. MG Siegler, a well-known tech journalist commented on this:

We've seen dozens of apps that are approved the first time, but later rejected for a seemingly small update.

And we've seen others that are rejected, make almost no change, yet get in the next time they're submitted. It would seem the life or death of an app is entirely in the hands of the App Store inspector who checks it out.

Sometimes they catch things that they don't want in the App Store, sometimes they do.

As response to third-party developers' concerns, Apple's senior vice president of worldwide product marketing, Phillip Schiller, stated on one of his private messages to a third-party developer of a rejected application that [August 6, 2009]:

Apple's goals remain aligned with customers and developers - to create an innovative applications platform on the iPhone and iPod touch and to assist many developers in making as much great software as possible for the iPhone App Store. While we may not always be perfect in our execution of that goal, our efforts are always made with the best intentions, and if we err we intend to learn and quickly improve.

Few months later [December, 2009], Apple started giving detailed feedback and comments to thirdparty developers. This was followed [January, 2010] by another action of speeding up the review process, which sometimes performed in less than three days. At the same time, AppStore review team was tightening the restriction on applications and banning any application that contained pornographic material. In an interview with New York Times [February 22, 2010], Philip Schiller, Apple's senior vice president of worldwide product marketing, said:

An increasing number of apps containing very objectionable content... It came to the point where we were getting customer complaints from women who found the content getting too degrading and objectionable, as well as parents who were upset with what their kids were able to see.

Steve Jobs emphasized this at the iPhone 4.o OS event [April 08, 2010] during a Q\&A session:

You know, there's a porn store for Android. You can download nothing but porn. You can download porn, your kids can download porn. That's a place we don't want to go - so we're not going to go there.

On September 9, 2010, Apple released the first set of a set of guidelines to third-party developers. The introductory section started with:

This is the first time we have published our App Store Review Guidelines. We hope they will help you steer clear of issues as you develop your app, so that it speeds through the approval process when you submit it. Less than a year later, Apple updated the AppStore guidelines to accommodate the new subscription models. The new guidelines document ended with clarification on why Apple isn't governing the AppStore and submitted applications:

Lastly, we love this stuff too, and honour what you do. We're really trying our best to create the best platform in the world for you to express your talents and make a living too. If it sounds like we're control freaks, well, maybe it's because we're so committed to our users and making sure they have a quality experience with our products. Just like almost all of you are too. 


\subsection{Enhancing the App Store}

The greatest strength of the AppStore is its huge number of applications. However, this is turning it into a weakness for many third-party developers and users. In fact, the huge number of applications makes it harder for third-party developers to market and promote their applications and harder for users to find the appropriate application they are looking for. Through continuous service and feature enhancements Apple adapted the AppStore to its huge growth. As part of the iPhone 3.1 firmware upgrade, Apple enhanced the AppStore with a new feature that allows users to search for new applications based on their previous purchase history. This feature goes by the name "Genius" and works as a recommendation system. At Apple's Rock and Roll special event [September 09, 2009], the "Genius" feature was one of two major services highlighted and praised by Steve Jobs:

Wouldn't it be great if the AppStore could recommendations of apps to you... and that's what Genius does now.... and it is really nice.... and this will only get better and better as we get larger databases of people, what they buy, what they like.

This was followed by enhancing the AppStore with another new feature labelled as "Top Grossing". This new feature enables users to view and explore the top grossing apps. It helps high quality and expensive grossing apps to get more exposure. It initially shows the 25 top grossing apps with the option to view more. At the same month [September 29, 2009] Apple rolled out a new feature called "Apps for Everything". The main concept behind is to allow users to find apps around certain categories of their interest and allow third-party developers to base their applications around certain relevant categories. One of the main concerns of users when purchasing from the AppStore is the workability and the quality of the app. Apple [December 11, 2009] redesigned the individual app description page. Instead of being text-heavy and one app screenshot, Apple changed the way third-party developers do their descriptions and allow multiple app screenshots. About a year later [August 05, 2010], Apple added a new section in the AppStore called "Try Before You Buy", that would serve both users and third-party developers. This service enables users to try a demo lite of the app before deciding whether they want to purchase it or not.

In order to help third-party developers spreading their applications and boost their revenues, Apple released two main features for the AppStore. The first feature allows third-party developers to use promotional codes that can be redeemed later by users and give them the chance to use the application with no additional cost. The other is the "Gift This App" feature [March 22, 2010] for the AppStore. This feature enables users to buy and gift applications for friends or family. While the AppStore is growing and the number of applications reached 550,000 applications that were downloaded about 25 billion times [February, 2012], the functionality of searching and discovering applications remained the biggest problem. Most recently [February 23, 2012], Apple acquired app search and discovery platform "Chomp" for about $\$ 50$ million. This acquisition revamps the AppStore search and recommendations services.

\section{Discussion}

In this paper, the main aim was to provide empirically grounded understanding of strategizing practices used by platform owners in attempts to create and sustain their digital application marketplaces. The following table describes three key strategies including monetizing, governing, and enhancing together with proactive or reactive strategic practices and associated strategic moves.

Table 3. Strategizing in digital applications marketplaces

\begin{tabular}{|l|l|l|}
\hline Strategy & $\begin{array}{l}\text { Strategic } \\
\text { Practice }\end{array}$ & \multicolumn{1}{c|}{ Strategic Moves } \\
\hline \multirow{3}{*}{ Monetizing } & & $\begin{array}{l}\text { 1. Applied the 30\% transaction cut of application sales revenues. } \\
\text { 2. Introduced the developer program and set the registration at \$99 for individual } \\
\text { developers and \$299 for enterprises. } \\
\text { 3. Released the In-App purchase service for paid applications and applied the 30\% } \\
\text { transaction cut. }\end{array}$ \\
& 4. Released the In-App purchase service for free applications and applied the 30\% \\
Proactive \\
monetizing \\
\end{tabular}




\begin{tabular}{|c|c|c|}
\hline & $\begin{array}{l}\text { Reactive } \\
\text { monetizing }\end{array}$ & $\begin{array}{l}\text { 1. Updated the refund policy: requires developers to refund the full sale amount } \\
\text { and Apple keeps its commission. } \\
\text { 2. Lowered the initial starting price of an iAd campaign to } \$ 0.5 \text { million. } \\
\text { 3. Lowered the initial starting price of an iAd campaign to } \$ 300,000 \text {. } \\
\text { 4. Lowered the initial starting price of an iAd campaign to } \$ 100,000 \text {. } \\
\text { 5. Lowered the iAd transaction cut to } 30 \% \text {. }\end{array}$ \\
\hline \multirow[t]{2}{*}{ Governing } & $\begin{array}{l}\text { Proactive } \\
\text { governing }\end{array}$ & $\begin{array}{l}\text { 1. Set the initial applications review process. } \\
\text { 2. Introduced the non-disclosure agreement (NDA). } \\
\text { 3. Tightened the restriction on applications. } \\
\text { 4. Released the first set of a set of guidelines to third-party developers. } \\
\text { 5. Updated the AppStore guidelines to accommodate the new subscription models. }\end{array}$ \\
\hline & $\begin{array}{l}\text { Reactive } \\
\text { governing }\end{array}$ & $\begin{array}{l}\text { 1.Dropped the non-disclosure agreement (NDA). } \\
\text { 2. Started giving detailed feedback and comments to third-party developers. } \\
\text { 3. Sped up the review process. }\end{array}$ \\
\hline \multirow[t]{2}{*}{ Enhancing } & $\begin{array}{l}\text { Proactive } \\
\text { enhancing }\end{array}$ & $\begin{array}{l}\text { 1. Released the AppStore with the "Genius" feature. } \\
\text { 2. Released the "Top Grossing" feature. } \\
\text { 3. Rolled out the "Apps for Everything" service. } \\
\text { 4. Acquired app search and discovery platform "Chomp". }\end{array}$ \\
\hline & $\begin{array}{l}\text { Reactive } \\
\text { enhancing }\end{array}$ & $\begin{array}{l}\text { 1. Redesigned the individual app description page. } \\
\text { 2. Released the “"Try Before You Buy" service. } \\
\text { 3. Allowed third-party developers use promotional codes. } \\
\text { 4. Released the "Gift This App" service. }\end{array}$ \\
\hline
\end{tabular}

Monetizing: It is defined as the generation of new business opportunities through the digital application marketplace. Monetizing can either be proactive or reactive. Proactive monetizing refers to the creation of new lines of business for enriching the digital application marketplace owner with new funding opportunities. It is observed how Apple built new sources of income by initiating nine different services. Apple requested 30\%-40\% transaction cut of the purchase each time applications, contents or subscriptions were sold through the AppStore. Further, they created another source of revenue by introducing the developer program and set memberships fees for thousands of individual third-party developers and developing enterprises. Apple lowered the initial starting price of an iAd campaign three times during the case to attract small advertisers or to deal with advertisers who have gone to other ad services. In this way, both reactive and proactive monetizing reflect flexible and agile strategizing process (El Sawy, 2010) by Apple as it accommodates opportunities (Orlikowski, 1996) and meets stakeholders' needs (Bosch, 2009; Messerschmitt and Szyperski, 2003).

Governing: The analysis shows that governing is an important strategy for digital application marketplace owners. Controlling the digital application marketplace and being responsible of what applications and services can be deployed and distributed is referred to as Governing. In a digital application marketplace that involves multiple actors, it is necessary to emphasize on governing - a verb -, rather than governance, as a continuous process (Orlikowski, 1996) to act upon any possibility for messy interactions and relationships (Galliers, 2007, Besson \& Rowe, 2012). Governing can therefore be either proactive or reactive. Governing is proactive if it involves actions that tighten the degree of accepting applications and dealing with them during the review process. Apple, for example, introduced the non-disclosure agreement (NDA) that made the review process very tough and the amount of comments and feedback very limited. Governing can also be reactive. In order to respond to third-party developers and authorities' requests, Apple relaxed their review process, sped up response time and started giving detailed comments and feedbacks to third-party developers.

Enhancing: Enriching the digital application marketplace with new capabilities and features is another key strategy. This strategy is referred to as Enhancing. Such enhancing is proactive when it involves releasing new capabilities and features that affect the efficiency of the AppStore and facilitate its functionality. For instance, Apple released the "Genius", "Top Grossing" and "Apps for Everything" features and managed to enhance the functionality of searching and discovering applications. The acquisition of the search and discovery platform "Chomp" is another strategic move towards the establishment of new and improved search environment for the AppStore. Enhancing can be reactive. Enhancing as strategizing practice embodies both deliberate and emergent strategizing (Whittington 2006; Mintzberg, 1978; Pettigrew, 1992). Digital application marketplaces are built on digital features and capabilities by the marketplace owner who strives to continuously monitor and evolve its digital infrastructure. This is necessary for initiating digital business and also sustaining the entire ecosystem.

\section{Conclusions and implications}

Our research offers a number of key conclusions and implications regarding the study of strategizing practices in digital application marketplaces. It was found that digital applications marketplace owners 
identify, configure, enact, and practice several strategies in attempts to develop and maintain their business. Three main strategies that can be enacted either proactively or reactively were synthesized in this paper including monetizing, governing and enhancing. These strategies show that strategizing in digital application marketplaces is enabled by a series of different strategies that jointly determine its relative success together with the digital platform. This is why platform owners should continuously monitor the evolution of the digital application marketplace to be able to develop strategic moves for new opportunities or to react to other actors' strategic moves. These conclusions have a number of implications for advancing existing literature and future research: first, it complements and extends the literature on digital platforms (Baldwin and Woodard 2009; Franke and von Hippel 2003; Morris and Ferguson 1993; Tiwana et al. 2010; West 2003; Yoo et al. 2010) by applying a strategy-as-process perspective (Chia and MacKay 2007; Johnson et al. 2003; Jarzabkowski 2008; Whittington 2006) in digital application marketplaces. Second, this study identified three main strategies which offer a new perspective on the nature of strategy in the context of digital application marketplaces and platforms. Finally, future research is needed for comparing different digital application marketplaces and their strategizing practices.

\section{References}

Ackoff, R.L. (1974). Redesigning the Future: A Systems Approach to Societal Problems. New York : John Wiley and Sons.

Amberg, M., Thiessen, I., Lang, M., and Belkius, B., (2010) Mobile Application Marketplaces - an Investigation from Customers' Perspective. In proceeding of MKWI 2010.

Baldwin, C. and Clark, K. (2000), Design Rules, Vol. 1: The Power of Modularity, Cambridge, MA: MIT Press.

Baldwin, C. and J. Woodard. (2009). The Architecture of Platforms: A Unified View. A. Gawer, ed. Platforms, Markets and Innovation. Edward Elgar, London, UK.

Benbasat, I., Goldstein, D. K., and Mead, M. "The Case Research Strategy in Studies of Information Systems," MIS Quarterly (11:3), 1987, pp. 369-386.

Benson, J. Kenneth 1977 "Organizations: A dialectical view.” Administrative Science Quarterly, 22: 1-21.

Bergvall-Kåreborn, B., and Howcroft, D. (2011) Mobile Applications Development on Apple and Google Platforms, Communications of the Association for Information Systems, 29 (1), Article 30.

Besson, P. and Rowe, F., 2012. Strategizing information systems-enabled organizational transformation: A transdisciplinary review and new directions. The Journal of Strategic Information Systems, 21(2), pp.103-124.

Bosch, J. (2009) From Software Product Lines to Software Ecosystems. The 13th International Software Product Line Conference (SPLC 2009), San Francisco, CA, USA.

Boudreau, K. 2012. Let a thousand flowers bloom? An early look at large numbers of software app developers and patterns of in novation. Organization Science , 23(5): $1409-1427$.

Bresnahan, T. F., Davis, J. P., and Yin, P. 2013. "Economic value creation in mobile applications," The changing frontier: Rethinking science and innovation policy University of Chicago Press.

Charmaz, K. Constructing Grounded Theory: A Practical Guide through Qualitative Analysis. Thousands Oaks, CA: SAGE Publications, 2006.

Chia R. and McKay, B. (2007) 'Post-processual Challenges for the Emerging Strategy-as-Practice Perspective: Discovering Strategy in the Logic of Practice', Human Relations, 6o(1): 217-242.

Creswell, J.W., (2003). Research Design: Qualitative, Quantitative, and Mixed Methods Approaches, (2nd ed.) SAGE Publications, Thousand Oaks.

El Sawy, O.A., Malhotra, A., Park, Y., Pavlou, P.A., 2010. Seeking the configurations of digital ecodynamics: it takes three to tango. Information Systems Research 21 (4), 835-848.

Evans, D.S., Hagiu, A. and Schmalensee, R. (2006) Invisible Engines: How Software Platforms Drive Innovation and Transform Industries, Cambridge MA: MIT Press.

Franke, N. and E. von Hippel., (2003). "Satisfying Heterogeneous User Needs via Innovation Toolkits: The Case of Apache Security Software, " Research Policy 32(7) 1199-1215.

Galliers, R. D. (2007). Strategizing for Agility: Confronting Information Systems Inflexibility in Dynamic Environments. In Desouza, K. C. Agile Information Systems. Conceptualization, Construction, and Management. Burlington, MA: Butterworth-Heinemann.

Gerring, J., (2007) Case study research: Principles and practices. Cambridge, UK: Cambridge University Press.

Ghazawneh A (2011) The power of platforms for software development in open innovation networks. International Journal of Networking and Virtual Organisations9(2):140-154.

Ghazawneh, A., and Henfridsson, O. (2013) "Balancing Platform Control and External Contribution in Third-Party Development: The Boundary Resources Model,” Information Systems Journal.

Ghazawneh, A., Henfridsson, O. (2015) A Paradigmatic Analysis of Digital Application Marketplaces. Journal of Information Technology. o, 1-11. doi:10.1057/jit.2015.16

Ghazawneh, A. and Mansour, O., 2015. Value Creation in Digital Application Marketplaces: A Developers' Perspective. In Thirty Sixth International Conference on Information Systems, Fort Wort, Texas, 2015.

Han, SP., and Ghose, A. (2012). Estimating Demand for Applications in the New Mobile Economy. In: Proceedings of International Conference on Information Systems, ICIS. Orlando Florida, USA. Dec 2012. 
Hanseth, O., and Lyytinen, K. (2010) "Design Theory for Dynamic Complexity in Information Infrastructures: The Case of Building Internet," Journal of Information Technology (25:1), pp 1-19.

Hargadon, A.B., \& Douglas, Y. (2001) When Innovations Meet Institutions: Edison and the Design of the Electric Light. Administrative Science Quarterly, 46, 476-501.

Henfridsson, O. and Lind, M., 2014. Information systems strategizing, organizational sub-communities, and the emergence of a sustainability strategy. The Journal of Strategic Information Systems, 23(1), pp.11-28.

Henfridsson, O., and Lindgren. R., (2010). "User involvement in developing mobile and temporarily interconnected systems.” Inform. Systems Journal. (20:2) 119-135.

Henfridsson, O., Yoo, Y., Svahn, F., (2009). "Path Creation in Digital Innovation: A Multi-Layered Dialectics Perspective," Sprouts: Working Papers on Information Systems, 9(20). http://sprouts.aisnet.org/9-20

Huang, P., Ceccagnoli, M., Forman, C., and Wu, D.J., (2009) "When Do ISVs Join a Platform Ecosystem? Evidence from the Enterprise Software Industry". In Proceedings of International Conference on Information Systems (ICIS), Proceedings. Paper 161.

Iansiti, M., and Zhu, F., (2007) "Dynamics of Platform Competition: Exploring the Role of Installed Base, Platform Quality and Consumer Expectations" (2007 In Proceedings of International Conference on Information Systems (ICIS) 2007, Proceedings. Paper 38.

Jarzabkowski, P. 2008. Shaping strategy as a structuration process. Academy of Management Journal (51:4).pp. 621-650.

Johnson, G., L. Melin, and R. Whittington 2003 'Micro-strategy and strategizing towards an activity-based view'. Journal of Management Studies 40/1: 3-22.

Klein, H. and Myers, M. (1999) A Set of Principles for Conducting and Evaluating Interpretive Field Studies in Information Systems, MIS Quarterly, and 23(1): 67-93.

Magnusson, J. and Nilsson, A. (2013) Introducing app stores into a packaged software ecosystem: a negotiated order perspective, Int. J. Business Information Systems, 14 (2): 223-237.

Messerschmitt, D.G., and Szyperski, C. (2003). "Software Ecosystem: Understanding an Indispensable Technology and Industry," MIT press.

Meyer, M. H. and Seliger, R., (1998). Product platforms in software development, Sloan Management Review, Fall 1998, 40(1), 61-74.

Mintzberg, H., 1978. Patterns in strategy formation. Management Science 24 (9), 934-948.

Orlikowski, W.J., 1996. Improvising organizational transformation over time: a situated change perspective. Information Systems Research 7 (1), 63-92.

Orlikowski, W. J. (2000). Using Technology and Constituting Structures: A Practice Lens for Studying Technology in Organizations. Organization Science, 11(4), 404-428.

Patton, M. (2015). Qualitative research and evaluation methods.

Pettigrew, A.M., 1992. The character and significance of strategy process research. Strategic Management Journal $13,5-16$.

Porter, M.E. 1980. Competitive Strategy: Techniques for Analyzing Industries and Competition. New York: Free Press.

Romano, N. C., Donovan, C., Chen, H., \& Nunamaker, J. F. “A methodology for analyzing web-based qualitative data," Journal of Management Information Systems, (19:4), 2003, pp. 213-246.

Romberg, T., (2007), Software platforms - how to win the peace, Proceedings of the 40th Hawaii International Conference on System Sciences (HICSS-40), 1-10.

Rudmark, D., Ghazawneh, A. (2011): Third-Party Development for Multi-Contextual Services:On the Mechanisms of Control. In: European Conference on Information Systems (2011)

Tilson, D., Sørensen, C., and Lyytinen, K. (2013) "Platform Complexity: Lessons from the Mu-sic Industry". 46th Hawaii International Conference on System Sciences (HICSS). pp. 4625 - 4634.

Tiwana, A., Konsynski, B., and Bush, A., "Research Commentary: Platform Evolution: Coevolution of Platform Architecture, Governance, and Environmental Dynamics," Information Systems Research, (21:4), December 2010, pp. 675-687.

Walsham, G (1995) Interpretive case studies in IS research: nature and method, European Journal of Information Systems, 4(2): 74-81.

Weick, K.E., (1979) The Social Psychology of Organizing, 2d ed. Reading, MA: Addison-Wesley.

West, J. 2003. "How Open Is Open Enough? Melding Proprietary and Open Source Platform Strategies," Research Policy (32), pp 1259-1285.

West, J., and Mace, M. (2010) Browsing as the Killerapp: Explaining the Rapid Success of Apple's iPhone. Telecommunications Policy, 34, 270-286.

Whittington, R. (2006). Learning more from failure: Practice and process. Organization Studies, (27:12), pp. 19031906.

Whittington, R. (1996). Strategy as practice. Long range planning, 29(5), 731-735.

Whittington, R., 2014. Information systems strategy and strategy-as-practice: a joint agenda. The Journal of Strategic Information Systems, 23(1), pp.87-91.

Yin, R.K. Case Study Research: Design and Methods, (2009). Thousand Oaks: SAGE Publications.

Yoo, Y., Henfridsson, O., and Lyytinen, K., (2010) "Research Commentary: The New Organizing Logic of Digital Innovation: An Agenda for Information Systems Research,” Information Systems Research, (21:4), December, pp. 724-735. 